\title{
Identification of Flights for Cost-Efficient Climate Impact Reduction
}

\author{
Neil Y. Chen* \\ NASA Ames Research Center, Moffett Field, CA 94035 \\ Philippe G. Kirschen ${ }^{\dagger}$ \\ University of Michigan, Ann Arbor, MI 48109 \\ Banavar Sridhar $\ddagger$ \\ NASA Ames Research Center, Moffett Field, CA 94035 \\ Hok K. $\mathrm{Ng}^{\S}$ \\ University of California, Santa Cruz, Moffett Field, CA 94035
}

\begin{abstract}
The aircraft-induced climate impact has drawn attention in recent years. Aviation operations affect the environment mainly through the release of carbon-dioxide, nitrogen-oxides, and by the formation of contrails. Recent research has shown that altering trajectories can reduce aviation environmental cost by reducing Absolute Global Temperature Change Potential, a climate assessment metric that adapts a linear system for modeling the global temperature response to aviation emissions and contrails. However, these methods will increase fuel consumption that leads to higher fuel costs imposed on airlines. The goal of this work is to identify flights for which the environmental cost of climate impact reduction outweighs the increase in operational cost on an individual aircraft basis. Environmental cost is quantified using the monetary social cost of carbon. The increase in operational cost is considering cost of additional fuel usage only. For this paper, an algorithm has been developed that modifies the trajectories of flights to evaluate the effect of environmental cost and operational cost of flights in the United States National Airspace System. The algorithm identifies flights for which the environmental cost of climate impact can be reduced and modifies their trajectories to achieve maximum environmental net benefit, which is the difference between reduction in environmental cost and additional operational cost. The result shows on a selected day, $16 \%$ of the flights among eight major airlines, or 2,043 flights, can achieve environmental net benefit using weather forecast data, resulting in net benefit of around $\$ 500,000$. The result also suggests that the long-haul flights would be better candidates for cost-efficient climate impact reduction than the short haul flights. The algorithm will help to identify the characteristics of flights that are capable of applying cost-efficient climate impact reduction strategy.
\end{abstract}

\section{Introduction}

The aircraft-induced climate impact has drawn attention in recent years. ${ }^{1}$ To address the aviation environment impacts with the growing air traffic, various methods have been proposed. ${ }^{2-6}$ The largest environmental impacts for enroute air traffic comes from emissions of carbon-dioxide and nitrogen-oxides, and persistent contrail formations. It has been shown that commercial aircraft can reduce climate impact due to these factors by modifying their trajectories, although this often comes at the cost of increased fuel

\footnotetext{
${ }^{*}$ Research Aerospace Engineer, Systems Modeling and Optimization branch, MS 210-10, Senior Member.

† Student, University of Michigan.

${ }^{\ddagger}$ Senior Scientist for Air Transportation Systems, Aviation Systems Division, MS 210-10, Fellow.

$\S$ Senior Software Engineer, University Affiliated Research Center, MS 210-8, Member.
} 
consumption. ${ }^{7}$ Such an increase in fuel consumption represents an increase in the operational cost incurred by an airline.

The three largest environmental impacts for enroute air traffic include direct emissions of greenhouse gases such as carbon dioxide $\left(\mathrm{CO}_{2}\right)$, emissions of nitrogen oxides $\left(\mathrm{NO}_{X}\right)$, and persistent contrails. $\mathrm{CO}_{2}$ and $\mathrm{NO}_{X}$ emissions are a function of fuel burn therefore reducing fuel consumption results in emissions reductions. Various procedures have been proposed in the past to reduce the persistent contrail formation, including promising approaches based on changing aircraft flight altitudes. Mannstein ${ }^{8}$ proposed a strategy to reduce the climate impact of contrails significantly by only small changes in individual flight altitude. Williams ${ }^{9,10}$ proposed strategies for contrail reduction by identifying fixed and varying maximum altitude restriction policies. However, these restrictions generally imply more fuel burn, thus more emissions. Sridhar, ${ }^{11}$ Chen, ${ }^{12}$ and $\mathrm{Wei}^{13}$ proposed contrail reduction strategies by altering an aircraft's cruising altitude in a fuel-efficient way, but these strategies did not address the environmental impact from aircraft emissions. Recently, the Absolute Global Temperature Potential (AGTP), a climate assessment metric that adapts a linear system for modeling the global temperature response to aviation emissions and contrails, was introduced in Ref. 14 and 15 to study the combined effect of $\mathrm{CO}_{2}$ emissions and contrail formation on the reduction strategies. Chen et al. ${ }^{7}$ evaluate both the reduction in environmental cost and the increase in operational costs for the climate reduction strategy by applying the same flight altitude change for all aircraft in each of the twenty U.S. Air Traffic Control Centers. A detailed climate reduction method for individual aircraft was not addressed in that study.

This paper follows the research reported in Ref. 7 and develops an climate impact reduction algorithm for individual aircraft. The goal of this work is to identify flights for which the environmental cost of climate impact reduction outweighs the increase in operational cost on an individual aircraft basis. To determine this, the changes in cost imposed upon both the airlines and society are considered using the cost of fuel and the social cost of carbon ${ }^{16-18}$ by developing a trajectory modification algorithm that modifies individual aircraft trajectories. A trajectory modification algorithm has been developed to minimize the aircraft environmental cost by reducing AGTP ${ }^{14,15,19}$ due to both contrails and $\mathrm{CO}_{2}$ emissions. The increase in fuel consumption that leads to higher fuel costs imposed on airlines is also computed by the algorithm. This research aims to identify flights that yield the most environmental benefit for the least operational cost from climate impact reduction strategies.

The remainder of the paper is organized as follows. Section II provides a description of the climate impact model, the cost model, and the climate impact reduction method. Next, Section III shows the results and analyses of climate impact reductions for flights from eight different airlines. Finally, Section IV presents a summary and conclusions.

\section{Models and Methods}

\section{II.A. Climate Impact Model}

The climate response to aviation emission and contrails can be modeled as outputs from a series of linear dynamic systems. The carbon cycle models describe the changes to the $\mathrm{CO}_{2}$ concentration due to the transport and absorption of $\mathrm{CO}_{2}$ by the land mass and various ocean layers. The Radiative Forcing (RF) for $\mathrm{CO}_{2}$ emissions is made of a steady-state component and three exponentially decaying components. ${ }^{20}$

Contrails occur at different regions of the earth and add non-uniform sources of energy to the atmosphere. The latest estimates indicate that contrails caused by aircraft may be causing more climate warming today than all the residual $\mathrm{CO}_{2}$ emitted by aircraft. ${ }^{21}$ The net $\mathrm{RF}$ for contrails includes the effect of trapping outgoing longwave radiation from the Earth and that of reflecting incoming shortwave radiation from the sun. Energy Forcing (EF) is the net energy flux induced to the atmosphere by a unit length of contrail over its lifetime. Estimates of EF given the RF forcing due to contrails are described in Ref. 22. The EF is expressed as joules $/ \mathrm{km}$ of contrails.

$\mathrm{NO}_{X}$ increases the amount of ozone in the atmosphere while decreasing the amount of methane in the atmosphere. The amount of ozone produced depends on the lifetime of $\mathrm{NO}_{X}$ that varies from days to weeks in the upper troposphere. The RF associated with $\mathrm{NO}_{X}$ is made up of short-lived positive RF due to ozone and a negative RF due to methane and methane-induced ozone and the combined effect results in a net RF due to $\mathrm{NO}_{X} \cdot{ }^{23}$ Research in Ref. 6 shows $\mathrm{NO}_{X}$ has relatively small effect for the climate reduction strategies compared to $\mathrm{CO}_{2}$ and contrails, therefore its effect is ignored in this paper.

The lifetime associated with different emissions and contrails varies from a few hours to several hundred 
years. The impact of certain gases depends on the amount and location of the emission, and the decisionmaking horizon, $H$ in years, when the impact is estimated. These variations make it necessary to develop a common yardstick to measure the impact of various gases.

Several climate metrics have been developed to assess the impact of the aviation emissions. ${ }^{24}$ Using linear climate response models, the Absolute Global Temperature Potential (AGTP) measures the mean surface temperature change because of different aircraft emissions and persistent contrail formations. ${ }^{19}$ AGTP provides a way to express the combined environmental cost of $\mathrm{CO}_{2}$ and $\mathrm{NO}_{X}$ emissions, and contrails as a function of the fuel cost. For simplicity, the RF due to contrails is assumed to be independent of the location of the contrails. The near surface temperature change $\Delta T$ for each flight can be approximated as

$$
\Delta T=\Delta T_{C O_{2}}+\Delta T_{C o n},
$$

where $\Delta T_{\mathrm{CO}_{2}}$ is the contribution to AGTP from $\mathrm{CO}_{2}$ emissions in Kelvin $(\mathrm{K})$ and $\Delta T_{C o n}$ is the contribution to AGTP from contrails in K. $\Delta T_{\mathrm{CO}_{2}}$ is a linear function of the additional $\mathrm{CO}_{2}$ emissions and $\Delta T_{\mathrm{Con}}$ is a linear function of the contrail formation time. The coefficients of the linear functions, also known as pulse AGTP, depend on the linear models for RF, the specific forcing because of $\mathrm{CO}_{2}$, energy forcing because of contrails, energy balance model and the duration of the climate effect horizon. ${ }^{14}$ Using the coefficients described in Ref. 6, at the time horizon of $H$, Eq.(1) can be rewritten as

$$
\Delta T^{H}=\operatorname{AGTP}_{C_{2}}^{H} E_{C O_{2}}+\operatorname{AGTP}_{C o n}^{H} L_{C o n},
$$

where $\Delta T^{H}$ is the temperature changes due to both $\mathrm{CO}_{2}$ and contrails for the time horizon of $H$ in $\mathrm{K}$, $\mathrm{AGTP}_{\mathrm{CO}_{2}}^{H}$ is the coefficient of AGTP due to $\mathrm{CO}_{2}$ for the time horizon of $H$ in $\mathrm{K} / \mathrm{kg}$, $\mathrm{AGTP}_{C \text { on }}^{H}$ is the coefficient of AGTP due to contrails for the time horizon of $\mathrm{H}$ in $\mathrm{K} / \mathrm{km}, E_{\mathrm{CO}_{2}}$ is the amount of $\mathrm{CO}_{2}$ emissions in $\mathrm{kg}$, and $L_{C o n}$ is the contrail length in $\mathrm{km}$. A list of pulse AGTP coefficients used in this paper is shown in Table 1.

Table 1. Pulse AGTP values for $\mathrm{CO}_{2}$ and contrails for three different time horizons

\begin{tabular}{cccc}
\hline Time Horizon & $\mathrm{H}=10$ years & $\mathrm{H}=25$ years & $\mathrm{H}=100$ years \\
\hline $\mathrm{AGTP}_{\mathrm{CO}}^{H}, \mathrm{~K} / \mathrm{kg}$ & $6.0 \times 10^{-16}$ & $6.7 \times 10^{-16}$ & $5.1 \times 10^{-16}$ \\
$\mathrm{AGTP}_{\mathrm{Con}}^{\mathrm{H}}, \mathrm{K} / \mathrm{km}$ & $1.5 \times 10^{-13}$ & $3.0 \times 10^{-14}$ & $5.1 \times 10^{-15}$ \\
\hline
\end{tabular}

The details of the fuel burn, emissions, and contrail models are described in Ref. 12. The details of the climate model can be found in Ref. 6 .

\section{II.B. Cost Model}

The total social cost of fuel consumption is comprised of the private cost of paying for fuel, borne by airlines and in turn their passengers, and the external cost of environmental damage, borne by societies, present and future. The social cost of carbon (SCC) is the cost, in monetary terms, to society of emitting an additional metric ton of carbon dioxide. It is often used to determine how much investment should be undertaken in order to mitigate the effects of carbon dioxide emissions. It also represents the theoretical value of a carbon tax for a perfect market. This is particularly suitable because asking or requiring airlines to increase fuel costs to reduce contrail formation would be a form of tax on contrail-induced environmental damage. The United States Government combines results from the three most prominent climate models to determine a suitable measure for the social cost of carbon and recently adopted a value of $\$ 36$ United States Dollars (USD) in 2007 dollars, which is equivalent to $\$ 41$ USD in 2013 dollars. ${ }^{25}$ This is the value used for the purpose of this research. Fuel costs historically represent as much as $33 \%$ of aircraft operating costs with an increasing trend. The fuel cost for individual flights are likely to increase if otherwise-quasi-optimal trajectories are modified in a way that is detrimental to fuel efficiency so as to avoid contrail favorable regions. For the purpose of this work, the price of jet fuel of $\$ 4$ USD per US gallon was used in this paper.

The social cost of carbon can be used to quantify the environmental cost of $\mathrm{CO}_{2}$ emission. Using the social cost of carbon dioxide as an estimate of environmental cost of $\mathrm{CO}_{2}$, the additional contribution to 
environmental cost from $\mathrm{CO}_{2}$ emissions, $\Delta \mathrm{Cost}_{\mathrm{CO}_{2}}$, can be formulated as

$$
\Delta \operatorname{Cost}_{\mathrm{CO}_{2}}=S C C \cdot \frac{\Delta E_{\mathrm{CO}_{2}}}{1000},
$$

where SCC is the social cost of carbon in dollar per metric ton, and $\Delta E_{\mathrm{CO}_{2}}$ is the change in $\mathrm{CO}_{2}$ emissions in $\mathrm{kg}$. In order to quantify the environmental cost of contrails, the environmental cost of temperature changes, specifically one Kelvin of AGTP, was defined using the SCC and the AGTP coefficient of $\mathrm{CO}_{2}$ for time horizon $H$ years,

$$
E C K^{H}=\frac{S C C}{1000 \cdot \operatorname{AGTP}_{C O_{2}}^{H}},
$$

where $E C K^{H}$ is the equivalent environmental cost of temperature change in dollars per Kelvin for the time horizon of $H$ years. Assume that the surface temperature is reduced after the climate impact reduction $\left(\Delta T^{H}<0\right)$, the total environmental cost reduction $\Delta \operatorname{Cost}_{E n v}^{H}$ can be formulated as

$$
\Delta \operatorname{Cost}_{E n v}^{H}=E C K \cdot\left(-\Delta T^{H}\right) .
$$

Note that $\Delta \operatorname{Cost}_{E n v}^{H}$ is postive after the climate impact reduction. The environmental net benefit, $N B_{E n v}^{H}$, is defined as

$$
N B_{E n v}^{H}=\Delta \operatorname{Cost}_{E n v}^{H}-\Delta \text { Cost }_{O p r},
$$

where $\Delta$ Cost $_{O p r}$ is the additional operational cost of applying the climate impact reduction. Only the cost of additional fuel burn is considered as additional operational cost in this paper. If the environmental cost reduction $\Delta \operatorname{Cost}_{E n v}^{H}$ is greater than the additional operational cost $\Delta$ Cost $_{O p r}$, the environmental net benefit $N B_{E n v}^{H}$ is positive.

\section{II.C. Climate Impact Reduction}

A preliminary trajectory modification algorithm has been developed. The goal of the algorithm is to reduce the total AGTP effect of a flight by modifying its trajectory. Previous study in Ref. 7 shows that the climate effect can be reduced efficiently by applying the same flight altitude change for all aircraft in each of the twenty U.S. Air Traffic Control Centers. This algorithm follows that concept and focuses on modifying the flight profile for individual aircraft; it allows aircraft to deviate no more than one flight level (2,000 feet) above or below the original flight path. It is assumed airlines choose to fly at, or close to, each aircraft optimal operating conditions and, at least approximately, along the most fuel-efficient trajectory, given the weather and traffic conditions at the time of flight. Aircraft can potentially reduce climate impact by avoiding contrail favorable regions either by climbing to a higher cruise altitude of descending to a lower cruise altitude. For most typical commercial aviation cruise altitudes, flying higher will generally yield higher fuel efficiency. However, flight ceiling and mechanical safety constraints often limit aircraft maximum cruise altitudes.

The algorithm evaluates the environmental cost for the period of a flight cruise segment. The total environmental cost is calculated as the combined AGTP effect of $\mathrm{CO}_{2}$ emissions due to fuel consumption and persistent contrail production caused by flying through contrail regions. The algorithm allows the flight to make one altitude change, meaning climbing 2,000 feet or descending 2,000 feet then returning to the original cruise altitude. The algorithm computes the combined environmental cost and operational cost of all flight segments at the cruise altitude and 2,000 feet above and below it and finds the path that will maximize the environmental net benefit. If this alternative results an environmental net benefit, then the flight path is altered to incorporate this change. Figure 1 shows an example flight modification for one of the flights tested. The grey blocks represent the contrail regions. The contrail regions were computed based on the weather data at the aircraft's take-off time and are assumed to be static during the flight. The blue line is the original flight path and the green line is the new path after modification. As indicated in the figure, the new path tried to avoid the contrail regions by flying 2,000 feet lower than the original flight path. The new path will result in reduction in $\Delta T_{\mathrm{Con}}$ by avoiding the contrail regions but increase $\Delta T_{\mathrm{CO}_{2}}$ due to additional fuel burn at a given time horizon $H$. The net changes in $\Delta T^{H}$ is negative, meaning the net climate impact is reduced after the flight path modification. The environmental cost reduction $\Delta \operatorname{Cost}_{E n v}^{H}$ is increased because of the reduction in $\Delta T^{H}$, and the operational cost $\Delta$ Cost $_{O p r}$ is also increased because of the additional fuel burn. The net environmental benefit is the difference of the two costs. If the environmental cost saving is greater than the additional operational cost, it will result in environmental net benefit 


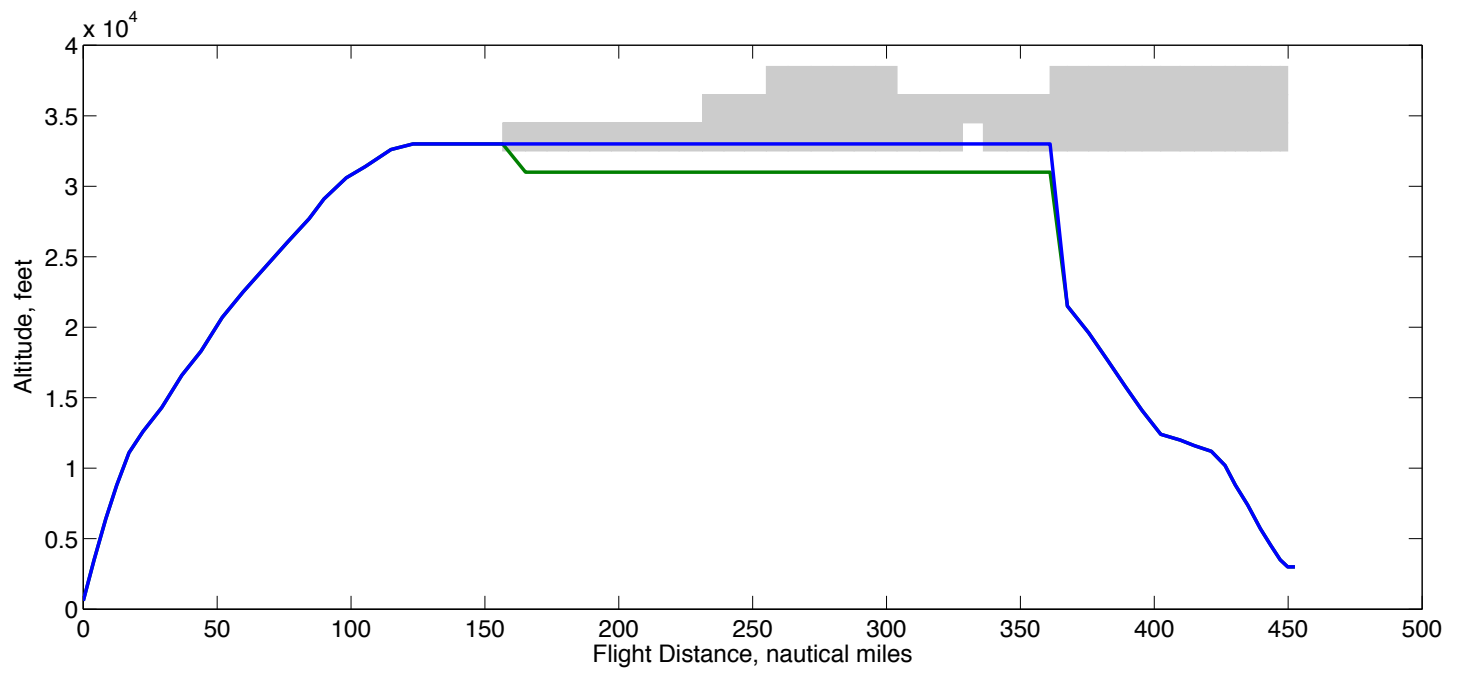

Figure 1. Flight profile (blue line: baseline, green line: after reduction) and contrail regions (grey areas) on April 23, 2010.

In reality, it is not possible to know the exact contrail regions to avoid before flying. The forecast data is required to predict the contrail regions so that the algorithm can determine the path to reduce the climate impact. Using actual weather data in the algorithm is like having perfect forecast data, which is not realistic. Figure 2 shows the same example of flight modification with the predicted and actual contrails regions. The grey blocks represent the contrail regions and the black grid blocks represent the predicted contrail regions. The predicted contrail regions were computed based on the one-hour weather forecast data at the aircraft's take-off time for the entire flight. The algorithm modified the flight trajectory based on predicted contrail regions, and use the actual contrail regions to determine the actual environmental cost. The blue line is the original flight path and the green line is the new path after modification. As indicated by the green line, because of the inaccuracy in the forecast data, the flight would fly through some contrail regions then lower the altitude before it reaches the black grid blocks. The flight would also fly back to the original cruise altitude after the predicted contrails regions is clear of contrails but the actual contrails still exist. It would still result in reduction in environmental cost but the benefit would be reduced because of the inaccuracy in the forecast data.

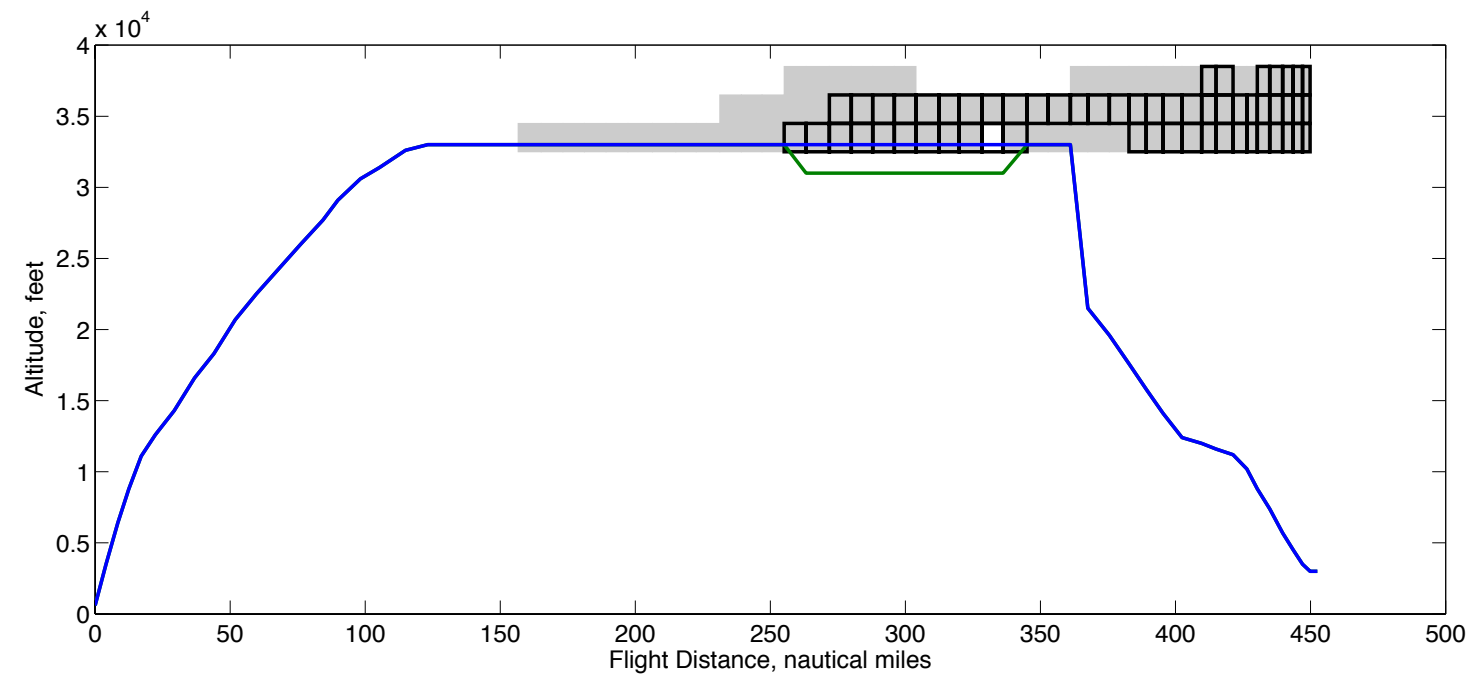

Figure 2. Flight profile (blue line: baseline, green line: after reduction), actual contrail regions (grey areas), and predicted contrail regions (black grids) on April 23, 2010. 


\section{Results}

\section{III.A. Using actual weather data}

The trajectory modification algorithm analyzed 12,787 flights using actual flight track data from the Enhanced Traffic Management System of April 23, 2010. These are all flights carried by one of eight major US airlines that operated the most flights on the day: American Airlines (AAL), America West Airlines (AWE), ExpressJet Airlines (BTA), Delta Airlines (DAL), American Eagle Airlines (EGF), SkyWest Airlines (SKW), Southwest Airlines (SWA), and United Airlines (UAL). The contrail model uses atmospheric temperature and humidity data retrieved from the Rapid Updated Cycle (RUC) data, provided by the National Oceanic and Atmospheric Administration (NOAA). The actual and one-hour forecast data based on the take-off time were used to find the contrail regions along each flight path. The day was selected because there were large portions of US airspace covered by the contrail regions. A time horizon of 25 years was used in the climate model; the study in Ref. 7 shows that the environmental benefit after applying the climate impact reduction strategy for time horizon of 25 years is more significant than for time horizon of 50 and 100 years. Figure 3 shows the additional operational cost (the fuel cost increase in this paper), against the environmental cost reduction using actual weather data for the flights with positive net benefit for each airline, in descending order of total net benefit, after the reduction strategy. Each blue dot represents a flight with net benefit (when the environmental cost reduction is greater than operational cost) greater than zero. From a policy perspective, the most desirable flight modifications reduce the net environmental cost by the most while increasing the fuel cost by the least, as these will result in the greatest net benefit. Graphically, these points can be found in the bottom-right corner of the figure. In the figure, Airlines \#1, \#2, and \#3 have a similar pattern. They show more blue dots at the bottom-right corner, while Airlines \#4, \#6, \#7, and \#8 show a similar pattern with less blue dots than the others and most of the dots are on the lower of the left-half side. This is mainly because Airlines \#1, \#2, and \#3 have more long-haul flights that will benefit more from climate impact reduction by avoiding long contrails. Airlines \#4, \#6, \#7, and \#8 have more short-haul flights therefore the environmental cost reduction of each flight is smaller. Airlines \#4, \#6 have more blue dots than Airlines \#7, and \#8 simply because they have more flights during the day. Airline \#5 has many short-haul flights and also some long- haul flights therefore the plot is a mix of the two patterns. These observations are consistent with the findings in Ref. 26. The climate impact reduction algorithm was able to achieve a net benefit for 3,067 of the 12,787 flights (24\%). The total net benefit is $\$ 843,416$, or equivalent to a reduction of around 20,000 tons of carbon emissions. The net benefit per flight is $\$ 275$. Among the 3,067 flights, there are 77 flights resulting in net benefit greater than $\$ 1,000$. The total net benefit among the 77 flights is $\$ 95,482$, or $\$ 1240$ per flight. These flights could be the most cost-efficient candidates for applying the climate reduction maneuver. The results for each of the eight airlines are summarized in Table 2. In the table, it shows Airline \#3 has the highest percentage of flights resulting in net benefit, at $43.1 \%$ even though the total net benefit is not the highest. This is because Airline \#3 has more long-haul and less short-haul flights than the others. Airlines \#1 and \#2 are next at 29.0\%, then Airline \#4 at 24.3\%. The other four airlines, which have mostly short-haul flights, have percentages less than $20 \%$. This suggests long-haul flights would be better candidates for climate impact reduction than the short haul flights.

Table 2. Number of flights and net benefit (NB) before and after climate reduction algorithm using actual weather data

\begin{tabular}{c|ccccc|cc}
\hline Airline & total flights & with NB & $\%$ & total NB & NB per flight & NB $>\$ 1000$ & total NB \\
\hline$\# 1$ & 2290 & 665 & $29.0 \%$ & $\$ 202,901$ & $\$ 305$ & 29 & $\$ 34234$ \\
$\# 2$ & 1801 & 522 & $29.0 \%$ & $\$ 147,772$ & $\$ 283$ & 7 & $\$ 8101$ \\
$\# 3$ & 1035 & 446 & $43.1 \%$ & $\$ 141,684$ & $\$ 318$ & 22 & $\$ 30236$ \\
$\# 4$ & 1706 & 415 & $24.3 \%$ & $\$ 105,976$ & $\$ 255$ & 8 & $\$ 9362$ \\
$\# 5$ & 1212 & 237 & $19.6 \%$ & $\$ 69,685$ & $\$ 294$ & 5 & $\$ 6042$ \\
$\# 6$ & 2159 & 340 & $15.7 \%$ & $\$ 63,912$ & $\$ 188$ & 3 & $\$ 3778$ \\
$\# 7$ & 1141 & 220 & $19.3 \%$ & $\$ 58,305$ & $\$ 265$ & 2 & $\$ 2318$ \\
$\# 8$ & 1443 & 222 & $15.4 \%$ & $\$ 53,181$ & $\$ 240$ & 1 & $\$ 1401$ \\
\hline Total & 12787 & 3067 & $24.0 \%$ & $\$ 843,416$ & $\$ 275$ & 77 & $\$ 95482$ \\
\hline
\end{tabular}



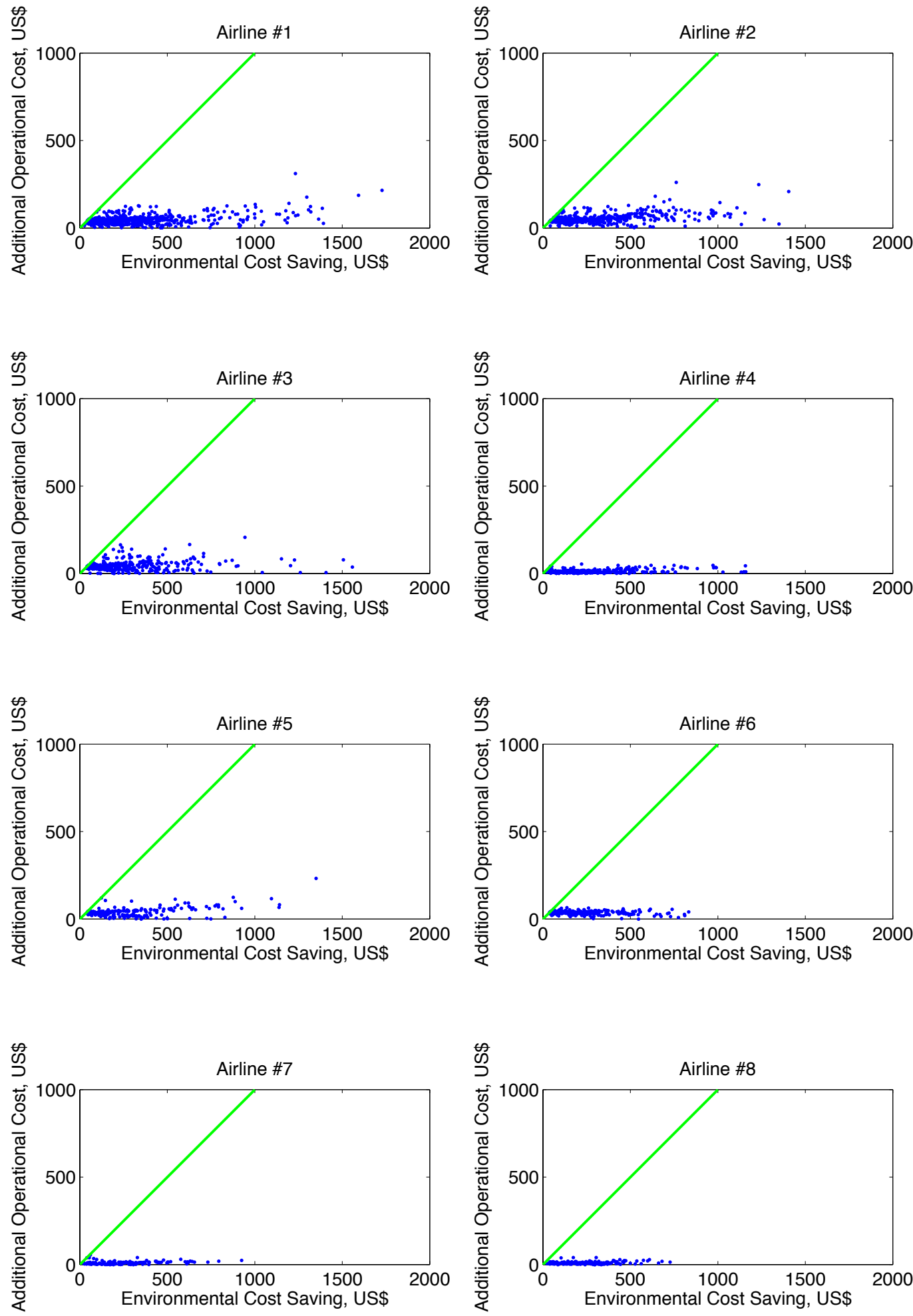

Figure 3. Additional operational cost versus the environmental cost reduction for the flights with positive net benefit using actual weather data on April 23, 2010. 


\section{III.B. Using forecast weather data}

In reality, it is not possible to know the exact contrail regions to avoid before flying. In this subsection, the one-hour forecast data based on the flight take-off time were used to predict the contrail regions. The climate reduction algorithm used the predicted contrail regions to modify the flight trajectories and used the actual weather data to compute the environmental cost reductions. Because of the inaccuracy in the forecast data, the performance of the climate reduction algorithm was reduced. Figure 4 shows the same example in Fig. 3 using forecast data for the algorithm. Because of the inaccuracy in the forecast data, it is possible that the flights would fly through some contrail regions or would climb or descend without contrail regions present, therefore resulting in lower environmental net benefit or even negative net benefit. It can be seen in the figure that the blue dots were shifted toward the left side compared to the blue dots in Fig. 3. The red dots represent the flights with negative net benefit, where the increases in the operational costs are larger than the environmental cost reductions. The flights with negative net benefit are the group of flights with small environmental cost reduction using actual data (bottom-left corner in Fig. 3). Only applying the algorithm to flights with large net benefit (blue dots on the right side) would avoid negative net benefits.

Using the one-hour forecast data, the climate reduction algorithm was still able to reduce the net benefit for 2,043 of the 12,787 flights (16\%) on the selected day; the algorithm identified 2,959 flights for climate reduction and 916 of them ended up with negative net benefit because of the inaccuracy of the forecast data. Also, among the 3,067 flights that could have received net benefit if actual weather data were used, 515 of them were not identified for a maneuver using forecast data. The total environmental net benefit was reduced from $\$ 843,416$ to $\$ 499,256$ when using forecast data compared to knowing the actual weather condition, which is a $41 \%$ reduction. The net benefit per flight for this one day was $\$ 169$. The results for each airline are summarized in Table 2. Using weather forecast data, Airlines \#1, \#2, and \#3 still result in the most total net benefits among the eight airlines, mainly because the three airlines have mostly long-haul flights. Airline \#3 remains having the most net benefit per flight. As indicated in the table, inaccurate forecast data have significant impact on the performance of the climate reduction algorithm for all airlines.

Table 3. Number of flights and net benefit (NB) before and after climate reduction algorithm using forecast weather data

\begin{tabular}{c|cccc|cc}
\hline Airline & total flights & identified flights & with neg. NB & missed flights & total NB & NB per flight \\
\hline$\# 1$ & 2290 & 674 & 235 & 139 & $\$ 121,351$ & $\$ 180$ \\
$\# 2$ & 1801 & 497 & 145 & 81 & $\$ 85,901$ & $\$ 173$ \\
$\# 3$ & 1035 & 435 & 128 & 65 & $\$ 90,672$ & $\$ 208$ \\
$\# 4$ & 1706 & 388 & 87 & 48 & $\$ 68,721$ & $\$ 177$ \\
$\# 5$ & 1212 & 215 & 60 & 29 & $\$ 40,522$ & $\$ 188$ \\
$\# 6$ & 2159 & 306 & 125 & 69 & $\$ 27,576$ & $\$ 90$ \\
$\# 7$ & 1141 & 231 & 67 & 53 & $\$ 35,155$ & $\$ 152$ \\
$\# 8$ & 1443 & 213 & 69 & 31 & $\$ 29,358$ & $\$ 138$ \\
\hline Total & 12787 & 2959 & 916 & 515 & $\$ 499,256$ & $\$ 169$ \\
\hline
\end{tabular}



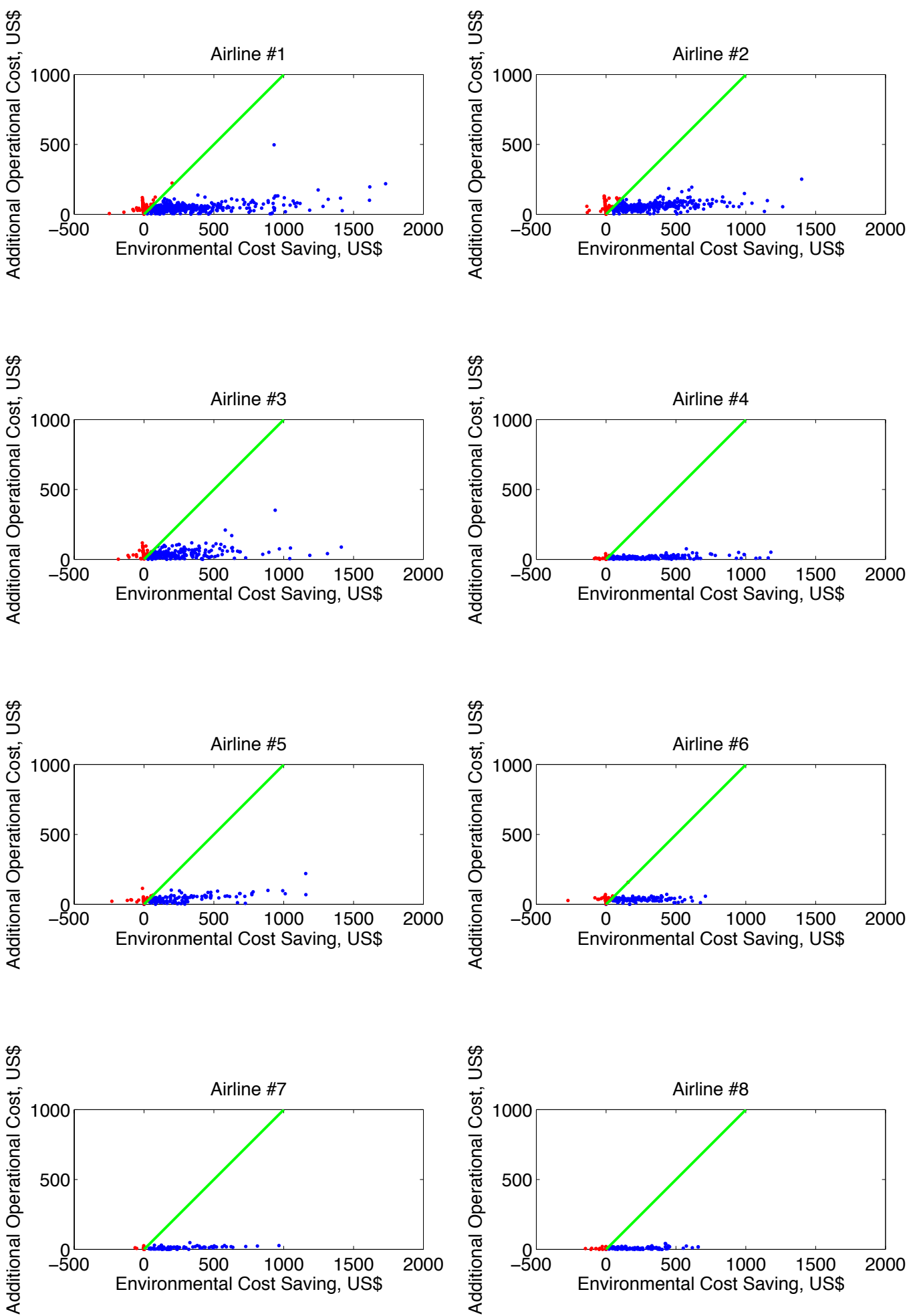

Figure 4. Additional operational cost versus the environmental cost reduction using forecast weather data on April 23, 2010. 


\section{Conclusions}

A algorithm has been developed that modifies the trajectories of individual flights to evaluate the effect of environmental cost and operational cost of flights in the United States National Airspace System. The algorithm identifies flights of which the environmental cost of climate impact reduction outweighs the increase in operational cost on an individual aircraft basis and modifies their trajectories to achieve the maximum environmental net benefit, which is the difference between the reduction in environmental cost and the additional operational cost. The result shows on a selected day, $24 \%$ of the flights can achieve environmental net benefit using actual weather data and $16 \%$ of the flights can achieve environmental net benefit using weather forecast data, resulting in net benefit of around $\$ 840,000$ and $\$ 500,000$, respectively. It also suggests that the long-haul flights would be better candidates in cost-efficient climate impact reduction than the short haul flights. Future work of this study includes using a more detail contrail model, ${ }^{27}$ designing more operational viable routing, and update the actual and forecast weather data along the flights.

\section{References}

\footnotetext{
${ }^{1}$ Waitz, I., Townsend, J., Cutcher-Gershenfeld, J., Greitzer, E., and Kerrebrock, J., "Report to the United States Congress: Aviation and the Environment, A National Vision, Framework for Goals and Recommended Actions," Tech. rep., Partnership for AiR Transportation Noise and Emissions Reduction, London, UK, December 2004.

${ }^{2}$ Schumann, U., Graf, K., and Mannstein, H., "Potential to reduce the climate impact of aviation by flight level changes," 3rd AIAA Atmospheric Space Environments Conference, AIAA, Honolulu, HI, June 2011.

${ }^{3}$ Kar, R., Bonnefoy, P., Hansman, R. J., and Sgouridis, S., "Dynamics of Implementation of Mitigating Measures to Reduce Commercial Aviation's Environmental Impacts," 9th AIAA Aviation Technology, Integration, and Operations Conference (ATIO), AIAA, Hilton Head, SC, September 2009.

${ }^{4}$ O'Neill, M. G., Dumont, J.-M., and Hansman, R. J., "Use of Hyperspace Trade Analyses to Evaluate Environmental and Performance Tradeoffs for Cruise and Approach Operations," 12th AIAA Aviation Technology, Integration, and Operations Conference (ATIO), AIAA, Indianapolis, IN, September 2012.

${ }^{5}$ Sridhar, B., Chen, N. Y., and Ng, H. K., "Energy Efficient Contrail Mitigation Strategies for Reducing the Environmental Impact of Aviation," Tenth USA/Europe Air Traffic Management Research and Development Seminar, Chicago, IL, June 2013.

${ }^{6}$ Sridhar, B., Chen, N. Y., and Ng, H. K., "Aircraft Trajectory Design Based on Reducing the Combined Effects of CarbonDioxide, Oxides of Nitrogen and Contrails," AIAA Modeling and Simulation Technologies (MST) Conference, National Harbor, MD, Jan 2014

${ }^{7}$ Chen, N., Sridhar, B., Ng, H., and Li, J., "Evaluating Tradeoff between Environmental Impact and Operational Costs for Enroute Air Traffic," AIAA Guidance, Navigation and Control Conference, AIAA, National Harbor, MD, January 2014.

${ }^{8}$ Mannstein, H., Spichtinger, P., and Gierens, K., "A note on how to avoid contrail cirrus," Transportation Research. Part D, Transport and environment, Vol. 10, No. 5, September 2005, pp. 421-426.

${ }^{9}$ Williams, V., Noland, R. B., and Toumi, R., "Reducing the climate change impacts of aviation by restricting cruise altitudes," Transportation Research. Part D, Transport and environment, Vol. 7, No. 6, November 2002, pp. 451-464.

${ }^{10}$ Williams, V. and Noland, R. B., "Variability of contrail formation conditions and the implications for policies to reduce the climate impacts of aviation," Transportation Research. Part D, Transport and environment, Vol. 10, No. 4, July 2005, pp. 269-280.

${ }^{11}$ Sridhar, B., Chen, N. Y., and Ng, H. K., "Fuel Efficient Strategies for Reducing Contrail Formations in United State National Air Space," 29th Digital Avionics Systems Conference, Salt Lake City, UT, October 2010.

${ }^{12}$ Chen, N. Y., Sridhar, B., and Ng, H. K., "Tradeoff between Contrail Reduction and Emissions in United States National Airspace," Journal of Aircraft, Vol. 49, No. 5, 2012, pp. 1367-1375.

${ }^{13}$ Wei, P., Sridhar, B., Chen, N., and Sun, D., "A Linear Programming Approach to the Development of Contrail Reduction Strategies Satisfying Operationally Feasible Constraints," AIAA Guidance, Navigation and Control Conference, AIAA, Minneapolis, MN, August 2012.

${ }^{14}$ Sridhar, B., Ng, H., and Chen, N., "Integration of Linear Dynamic Emission and Climate Models with Air Traffic Simulations," AIAA Guidance, Navigation and Control Conference, AIAA, Minneapolis, MN, August 2012.

${ }^{15}$ Sridhar, B., Ng, H., and Chen, N., "Uncertainty Quantification in the Development of Aviation Operations to Reduce Aviation Emissions and Contrails," 28th International Congress of the Aeronautical Sciences, AIAA, Brisbane, Australia, September 2012.

${ }^{16}$ Greenstone, M., Kopits, E., Wolverton, A., Greenstone, M., Kopits, E., and Wolverton, A., "Estimating the Social Cost of Carbon for Use in U.S. Federal Rulemakings: A Summary and Interpretation," 2011.

${ }^{17}$ California Environmental Protection Agency, A. R. B., "California Air Resources Board Quarterly Auction 2," 2013.

${ }^{18}$ Klein, R. J., Huq, S., Denton, F., Downing, T. E., Richels, R. G., Robinson, J. B., and Toth, F. L., "Consideration of costs and damages avoided and/or benefits gained," In: Climate Change 200\%: Impacts, Adaptation and Vulnerability Contribution of Working Group II to the Fourth Assessment Report of the Intergovernmental Panel on Climate Change, edited by M. Parry, O. Canziani, J. Palutikof, P. van der Linden, and C. Hanson, Cambridge University Press, Cambridge, United Kingdom and New York, NY, 2007.

${ }^{19}$ Eyring, V., Isaksen, I. S., Berntsen, T., Collins, W. J., Corbett, J. J., Endresen, O., Grainger, R. G., Moldanova, J., Schlager, H., and Stevenson, D. S., "Transport impacts on Atmosphere and Climate: Metrics," Atmosphere Environment, Vol. 44, No. 37, 2010, pp. 4648-4677.
} 
${ }^{20}$ Forster, P., Ramaswamy, V., Artaxo, P., Berntsen, T., Betts, R., Fahey, D., Haywood, J., Lean, J., Lowe, D., Myhre, G., Nganga, J., Prinn, R., Raga, G., Schulz, M., and Dorland, R. V., "Changes in Atmospheric Constituents and in Radiative Forcing," In: Climate Change 2007: The Physical Science Basis. Contribution of Working Group I to the Fourth Assessment Report of the Intergovernmental Panel on Climate Change, edited by S. Solomon, D. Qin, M. Manning, Z. Chen, M. Marquis, K. Averyt, M.Tignor, and H. Miller, Cambridge University Press, Cambridge, United Kingdom and New York, NY, 2007.

${ }^{21}$ Boucher, O., "Atmospheric science: Seeing through contrails," Nature Climate Change, Vol. 1, 2011, pp. 24-25.

${ }^{22}$ Schumann, U., Graf, K., and Mannstein, H., "Potential to Reduce the Climate Impact of Aviation by Flight Level Changes," AIAA Modeling and Simulation Technologies Conference, AIAA-2011-3376, AIAA, Honolulu, HI, June 2011.

${ }^{23}$ Kohler, M., Radel, G., Shine, K., H.L.Rogers, and Pyle, J., "Latitudinal variation of the effect of aviation NO emissions on atmospheric ozone and methane and related climate metrics," Atmosphere Environment, Vol. 64, 2013, pp. 1-9.

${ }^{24}$ Fuglestvedt, J., Shine, K., Berntsen, T., Cook, J., Lee, D., Stenke, A., Skeie, R., Velders, G., and Waitz, I., "Transport impacts on atmosphere and climate: Metrics," Atmospheric Environment, Vol. 44, No. 37, 2010, pp. 4648 - 4677.

${ }^{25}$ United States Government, "Technical Support Document: - Technical Update of the Social Cost of Carbon for Regulatory Impact Analysis," Tech. rep., Under Executive Order 12866, Interagency Working Group on Social Cost of Carbon, May 2013.

${ }^{26}$ Chen, N., Sridhar, B., Li, J., and Ng, H., "Evaluating Tradeoff between Environmental Impact and Operational Costs for Enroute Air Traffic," AIAA Guidance, Navigation and Control Conference, AIAA, Minneapolis, MN, August 2012.

${ }^{27} \mathrm{Li}$, J., Caiazzo, F., Chen, N. Y., Sridhar, B., Ng, H., and Barrett, S., "Evaluation of Aircraft Contrails using Dynamic Dispersion Model," AIAA Guidance, Navigation and Control Conference, AIAA, Boston, MA, August 2013. 